\title{
Khan Academy: uma ferramenta de auxílio no processo de ensino/ aprendizagem da Matemática
}

\author{
Adriana Barroso de Azevedo* \\ César Augusto do Prado Moraes**
}

\section{Resumo}

O presente artigo sobre a experiência do uso da plataforma do Khan Academy constituiu uma das atividades previstas no planejamento das aulas de matemática do ensino fundamental em duas turmas de $6^{\circ}$ anos e em três turmas de $8^{\circ}$ anos durante o ano letivo de 2016. O objetivo deste trabalho foi analisar as narrativas dos alunos sobre o processo de uma experiência matemática que utilizou a plataforma do Khan Academy como uma ferramenta de auxílio do processo de ensino/aprendizagem da Matemática. Diante da análise das narrativas dos discentes, constatouse o uso da plataforma do Khan Academy como um recurso didáticotecnológico que permitiu a atuação constante da construção do conhecimento matemático dos alunos/participantes.

Palavras-chave: Khan Academy. Ensino/Aprendizagem. Matemática.

* Professora Doutora do Programa de Pós-Graduação em Educação da Universidade Metodista de São Paulo (UMESP) - São Bernardo do Campo. Pós Doutora em Educação, Doutora em Comunicação Social, Mestra em Educação, Graduada em Pedagogia. Contato: adriana.azevedo@metodista.br

** Doutorando em Educação no Programa de Pós-Graduação da Universidade Metodista de São Paulo (UMESP) - São Bernardo do Campo. Mestre em Educação, Graduado em Matemática e Pedagogia. Contato: cesarmatbori@, hotmail.com 


\section{Khan Academy: a useful tool in the process of teaching/learning mathematics}

\section{Abstract}

This study is aimed at the experience of usage of the Khan Academy platform, which composed one of the activities scheduled in the planning of Elementary School Mathematics classes in two 6th grade classes and in three 8th grade classes during the 2016 school year. The focus of this paper was to analyze students' narratives about the process of a mathematical experiment using the Khan Academy platform as an aid tool of the teaching/learning process of Mathematics. In face of the analysis of the students' narratives, it was concluded that the Khan Academy platform was used as a didactic-technological resource which allowed the constant performance of the mathematical knowledge construction of the students/participants.

Keywords: Khan Academy. Teaching/Learning. Mathematics.

\section{Khan Academy: una herramienta de apoyo en el proceso de enseñanza/aprendizaje de las Matemáticas}

\section{Resumen}

El presente artículo sobre la experiencia del uso de la plataforma de Khan Academy constituyó una de las actividades previstas en la planificación de las clases de Matemáticas de los $6^{\text {os }}$ y $8^{\text {os }}$ grados de la Enseñanza Básica durante el año escolar de 2016. Participaron estudiantes de dos salones del $6^{\circ}$ grado y de tres salones del $8^{\circ}$ grado. El objetivo de este estudio fue analizar las narraciones de los alumnos sobre el proceso de una experiencia matemática que utilizó la plataforma Khan Academy como herramienta de apoyo al proceso de enseñanza-aprendizaje de las Matemáticas. Se constató, mediante análisis de los relatos de los alumnos, que el uso de la plataforma Khan Academy, como un recurso didáctico y tecnológico, facilitó el contacto frecuente de los aestudiantes con los contenidos de la asignatura, lo que contribuyó a la construcción del conocimiento matemático de los alumnos que participaron de esta investigación.

Palabras clave: Khan Academy. Enseñanza/Aprendizaje. Matemáticas. 


\section{Introdução}

A utilização da plataforma do Khan Academy como auxílio no processo de ensino/aprendizagem da Matemática constituiu uma das atividades previstas no planejamento das aulas de Matemática do Ensino Fundamental em duas turmas de $6^{\circ}$ anos e em três turmas de $8^{\circ}$ anos durante o ano letivo de 2016. Para tanto, foi cadastrada na plataforma em questão cada turma/sala e seus respectivos alunos com o intuito de ajudar a explorar os temas do componente curricular, de acordo com o ano de estudo em questão, correspondentes aos conteúdos matemáticos estudados e aprendidos em sala de aula.

A experiência aqui relatada foi realizada em uma escola da Zona Leste de São Paulo que oferece, nos períodos matutino e vespertino, turmas do $6^{\circ}$ ao $9^{\circ}$ ano do Ensino Fundamental e, no período noturno, turmas de $1^{\mathrm{a}}$ a $3^{\mathrm{a}}$ série do Ensino Médio na modalidade de Ensino Supletivo (EJA) e compõe uma das unidades escolares da Rede de Ensino do Estado de São Paulo.

A escolha das turmas deveu-se ao fato de que um dos autores deste relato de experiência é professor efetivo de Matemática há quase 14 anos nessa escola e, por isso, conhece todos os professores, alunos, gestores e boa parte da comunidade escolar, garantindo a possibilidade de analisar as narrativas coletadas que são os dados deste trabalho, entre as quais inclui a própria prática como docente, uma vez que um dos autores enfrenta, junto com os alunos/ participantes, todos os desafios do cotidiano escolar.

Passeggi e Souza (2010, p. 16) evidenciam a importância e a possibilidade de uma melhor observação do pesquisador quando também é o próprio pesquisado. Segundo os autores, relatar uma experiência de sua própria prática e de seu ambiente de trabalho cria espaços para produzir "conhecimentos que favoreçam o aprofundamento teórico sobre a formação do humano e, enquanto prática de formação, conduzir o diálogo de modo mais proveitoso consigo mesmo, com o outro e com a vida". 
As cinco turmas escolhidas como alunos/participantes deste trabalho possuem um total de 140 discentes; sendo 84 alunos do $8^{\circ}$ ano e 56 alunos do $6^{\circ}$ ano, todos adolescentes de classe média, entre a faixa etária de 10 e 16 anos, que apresentavam um comportamento estável; possuíam uma grande interação uns com os outros e também com todo o corpo docente, gestores escolares e funcionários da unidade escolar. As turmas eram tipicamente classificadas pelo corpo docente como tranquilas e de fácil efetuação do trabalho escolar.

O objetivo deste trabalho foi analisar as narrativas dos alunos sobre o processo de uma experiência matemática que utilizasse a plataforma do Khan Academy, uma ferramenta de auxílio do processo de ensino/aprendizagem da Matemática.

Neste sentido, o relato desta experiência do uso da plataforma do Khan Academy concentra em uma possibilidade de utilizar recursos tecnológicos nas aulas de matemática em uma perspectiva de "sala de aula ampliada"(AZEVEDO;PERICO, 2016) que concedem a construção do conhecimento matemático onde o professor exerce a função de mediador e tutor dos conteúdos matemáticos ensinados, reunindo assim as habilidades que os alunos do século XXI dominam e se interessam, conduzindo a uma aprendizagem mais significativa e contextualizada.

Este artigo é parte dos resultados obtidos numa pesquisa de doutorado em fase de desenvolvimento, na qual relatamos uma das atividades de experiência com o uso de tecnologia no ensino de matemática do Ensino Fundamental.

\section{O uso da plataforma do Khan Academy}

A plataforma Khan Academy foi gerada por Salman Khan no ano de 2006, propiciando um novo olhar metodológico para o ensino das ciências (Matemática, Biologia, Química e Física) por contribuir para, segundo o próprio Khan (2013, p. 206), "uma educação gratuita, universal, para todo mundo, em todo lugar".

Essa plataforma de recurso educacional on-line, disponível na internet e de acesso gratuito, oferece videoaulas e exercícios de 
Matemática que atendem desde a Educação Infantil até o Ensino Superior.

Menegais; Fagundes e Sauer (2015, p. 02) apresentam a proposta primordial do Khan Academy sob o conceito de que os

[...] estudantes aprendem por meio de videoaulas sobre diversos conteúdos, dentre eles a Matemática, de acordo com seu próprio ritmo, e um software no qual cada um pode acompanhar sua evolução de aprendizagem, com os professores acompanhando o desempenho de toda a turma na realização das atividades.

A plataforma Khan Academy oferece a possibilidade de o professor acompanhar em tempo real o desempenho dos estudantes, por meio do software disponibilizado pela plataforma, com formato de videogame, recursos [...] que são pouco enfatizados e caracterizam seu diferencial com relação a outras plataformas de aprendizagem.

Mediante esse esclarecimento da proposta educacional da plataforma Khan Academy, utilizamos o recurso em uma das atividades com o $6^{\circ}$ e o $8^{\circ}$ anos buscando incentivar a utilidade das novas tecnologias da informação e comunicação no ambiente escolar.

A plataforma Khan Academy foi empregada junto aos alunos/participantes uma vez por semana durante o ano letivo de 2016, no laboratório de informática na escola escolhida para a realização deste trabalho de pesquisa. O espaço era constituído por sete computadores, portanto, as turmas foram divididas em grupos de seis a sete discentes e atribuídos a eles um computador para que buscassem a resolução dos exercícios propostos e assistissem aos vídeos disponíveis na plataforma. Seguem as fotos do laboratório de informática e dos grupos dos alunos. 
Figura 1: Laboratório de Informática

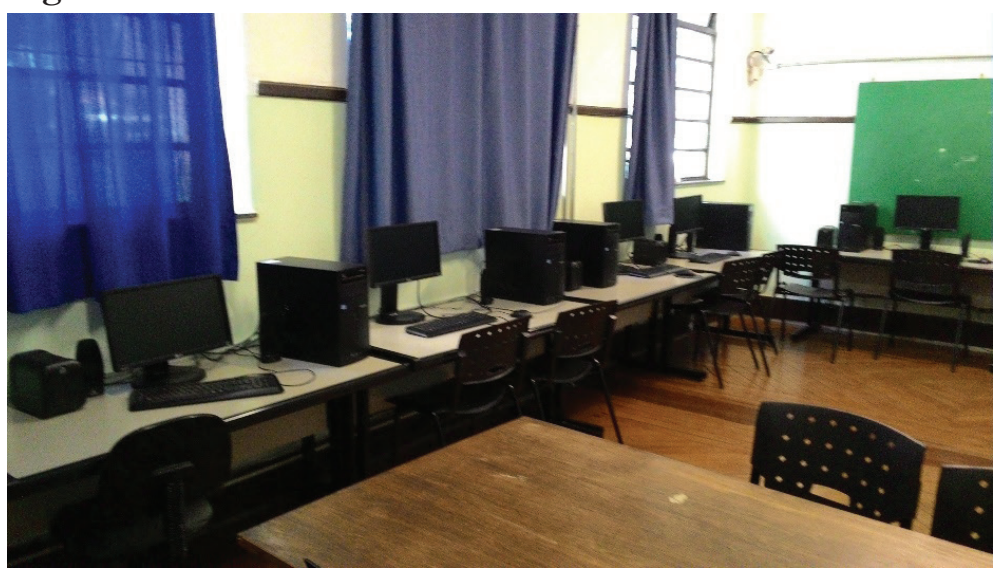

Fonte: Acervo do autor

Figura 2: Alunos/participantes do $6^{\circ}$ ano no Laboratório de Informática

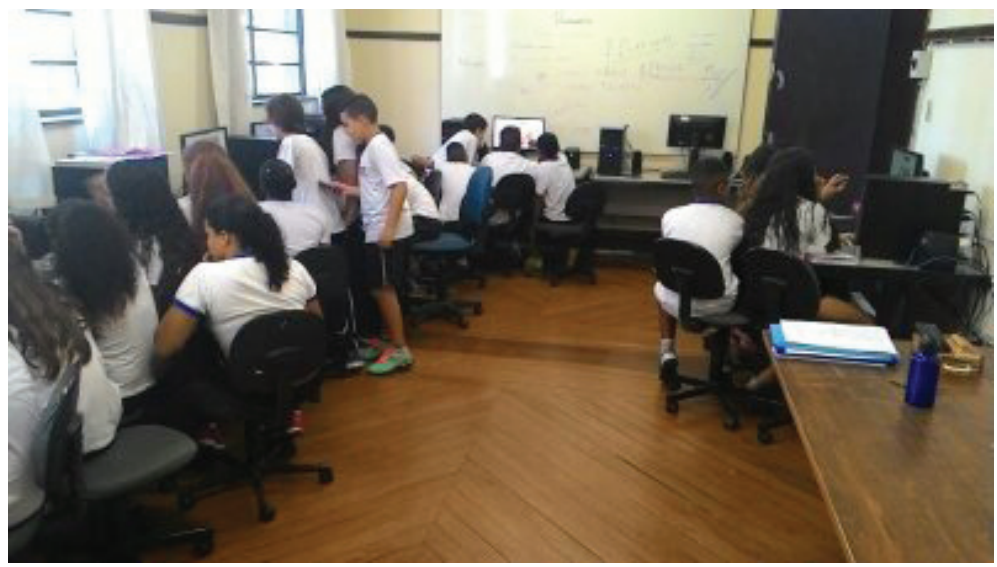

Fonte: Acervo do autor 
Figura 3: Alunos/participantes do $8^{\circ}$ ano no Laboratório de Informática

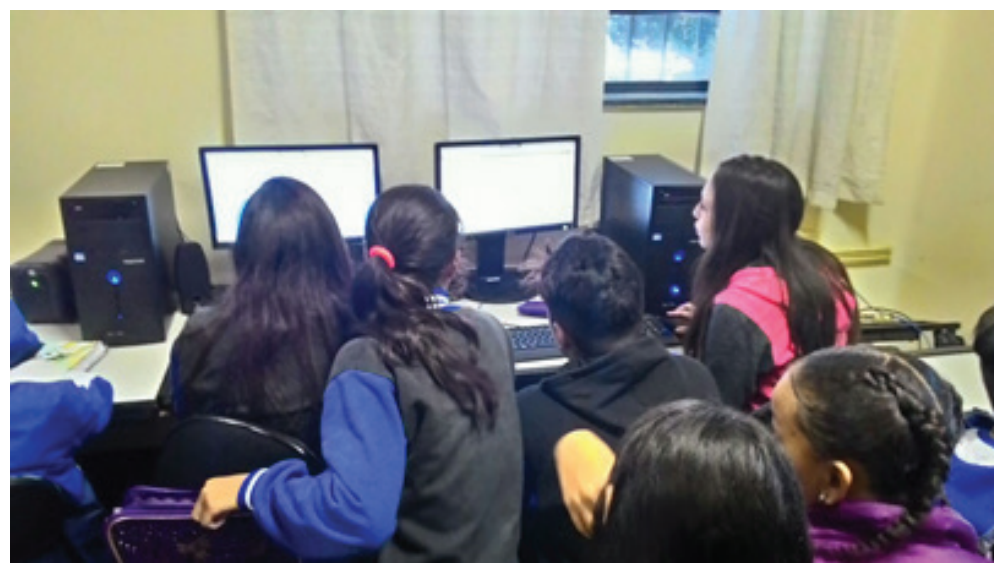

Fonte: Acervo do autor

Como se pode observar nas fotos anteriores, apesar de o laboratório de informática possuir somente sete computadores, os alunos/participantes estabeleceram um envolvimento harmonioso na realização dos exercícios propostos pela plataforma Khan Academy. Dessa maneira, os discentes assumiram uma legítima condição de sua aprendizagem matemática transformando-se "em reais sujeitos da construção e da reconstrução do saber ensinado" (FREIRE, 2011, p. 26).

Uma ressalva importante sobre a utilização da plataforma é que, durante os quatro bimestres do ano letivo de 2016, foi realizada uma avaliação on-line em que eu, como tutor e professor das turmas, selecionava os conteúdos e monitorava a aprendizagem individual de cada um dos alunos/participantes. Essas avaliações foram organizadas a partir dos conteúdos ensinados em sala de aula, recomendados por mim para a realização de exercícios de apoio ao processo de aprendizagem da Matemática na plataforma Khan Academy, e sugeridas que fossem realizadas uma vez por semana fora do espaço escolar. 
As referidas avaliações foram planejadas com uma sequência de cinco exercícios, tendo cada um o valor de dois pontos. Por a plataforma ser interativa e disponibilizar o recurso de apoio em forma de dicas, quando o discente buscasse ajuda, a pontuação passaria a ter o valor de um ponto na composição de seu rendimento final. A formulação dessa avaliação, e também das sequências de exercícios utilizadas no Khan Academy, possibilitou que eu estabelecesse um planejamento personalizado com relação aos conteúdos matemáticos, considerando as dificuldades de cada aluno/participante. Com isso, consegui formular uma avaliação que pudesse identificar e intervir nas dificuldades e nos déficits dos alunos em assimilar os conteúdos, além de estimular o progresso de seus rendimentos escolares.

Os alunos/participantes, no momento de avaliação na plataforma Khan Academy, puderam levar como material de apoio o caderno para a realização da resolução dos exercícios e o estojo constituído por seus lápis e canetas. Seguem as fotos de representação dessa avaliação.

Figura 4: Alunos/participantes do $6^{\circ}$ Ano realizando avaliação no Khan Academy

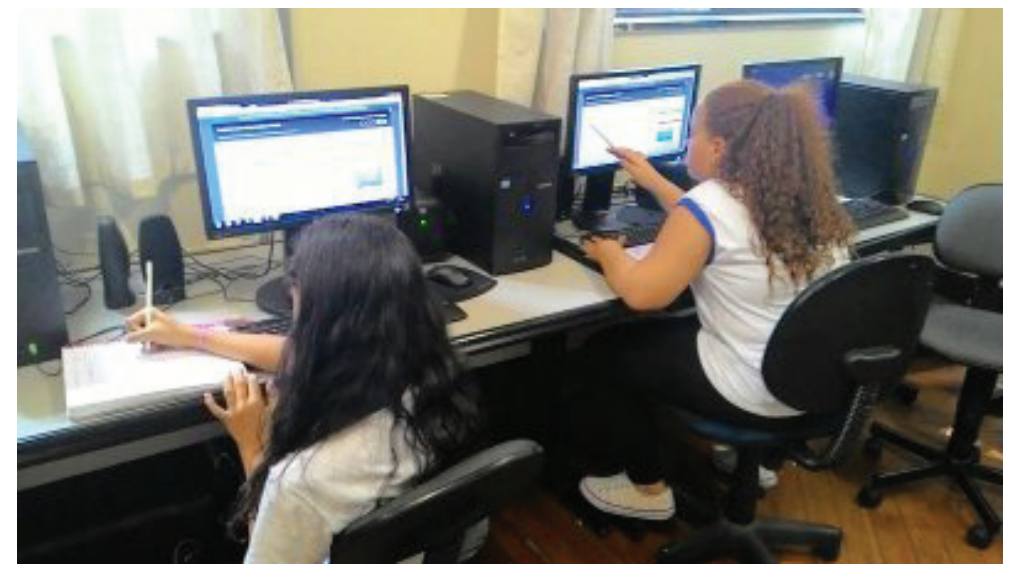

Fonte: Acervo do autor 
Figura 5: Alunos/participantes do $8^{\circ}$ Ano realizando avaliação no Khan Academy

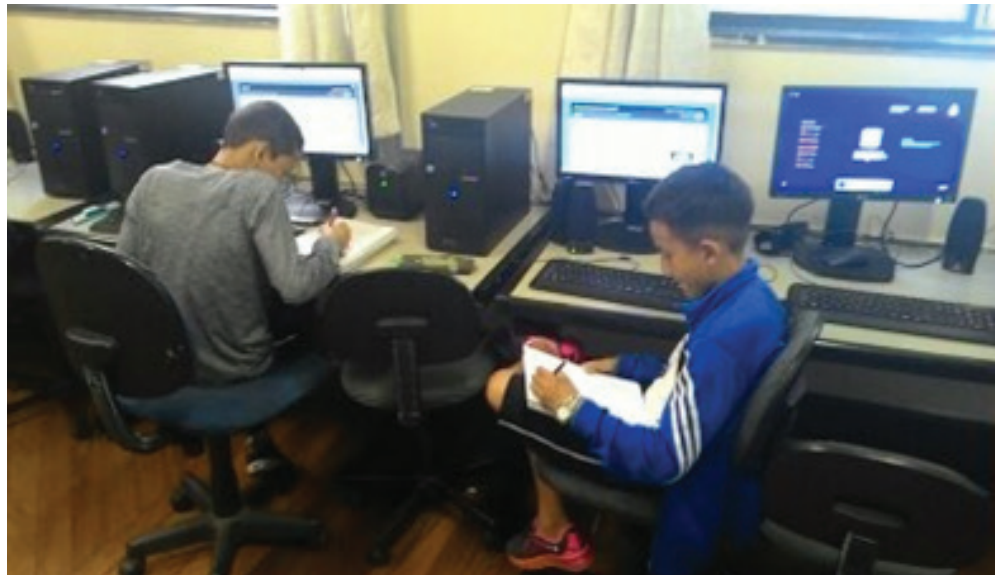

Fonte: Acervo do autor

A partir da apresentação das imagens que visualizamos durante a aplicação da avaliação on-line na plataforma Khan Academy, podemos ver também como essa atividade é "um exemplo do poder do ensino on-line de ajudar os professores a diferenciar e a customizar a aprendizagem para se adequar às necessidades de um estudante" (HORN; STAKER, 2015, p. 05).

Também utilizeias planilhas e os recursos de acompanhamento dos alunos/participantes que a plataforma disponibiliza ao tutor da turma, nomeadas de "relatório de progresso por habilidade" das turmas, enviado ao e-mail cadastrado pelo docente semanalmente. Nesse relatório o docente pode acompanhar as habilidades que os alunos possuem domínio e quais ainda precisam praticar, tendo também o tempo de acesso em minutos e os níveis de aprendizagem matemática de que fazem parte.

\section{Narrativas dos alunos/participantes como resultados da experiência}

Para trazer sentido a este trabalho de pesquisa a partir da metodologia de pesquisa autobiográfica na modalidade narrativa 
com os alunos/participantes adolescentes, busquei nas narrativas pontos relevantes da utilização do Khan Academy no processo de ensino/aprendizagem da Matemática. Nesse sentido, identifiquei um processo de "meta-reflexão do ato de narrar-se, dizer-se de si para si mesmo como uma evocação dos conhecimentos das experiências construídas” (SOUZA, 2004, p. 72).

Com a experiência do uso da plataforma Khan Academy, o professor teve o objetivo de mostrar aos alunos que os recursos tecnológicos podem ser utilizados para fins pedagógicos de forma diferenciada e prazerosa.

Para finalizarmos o relato desta experiência, coletamos as narrativas dos alunos/sujeitos deste trabalho com o intuito de verificarmos a interpretação autobiográfica formativa que permite aos discentes considerarem-se como narradores desta experiência.

Utilizamos a abordagem metodológica qualitativa na perspectiva autobiográfica na modalidade narrativa descritas por Josso (2010). A autora afirma que

\footnotetext{
uma narrativa centrada na formação e nas aprendizagens do seu autor, que não é classificada "auto" à medida que o indicador da narrativa é o investigador e, por fim, que o interesse da Biografia Educativa está menos na narrativa propriamente dita do que na reflexão que permite a sua construção (JOSSO, 2010, p. 66).
}

Como processo de reflexão na construção dessas narrativas dos alunos do $6^{\circ}$ ano e do $8^{\circ}$ ano, convidamos os discentes a descreverem as suas observações individuais sobre a experiência do uso da plataforma do Khan Academy, utilizando como instrumento de coleta de dados desta experiência. Para a escrita das narrativas, pontuamos uma questão norteadora: "Escreva sua opinião sobre o uso da plataforma do Khan Academy como uma ferramenta auxiliar para o processo de ensino/aprendizagem da Matemática". As escritas dos alunos foram conservadas na íntegra.

Em concordância com a discussão sobre a plataforma do Khan Academy como umas das atividades contidas no planejamento 
das aulas de matemática, utilizamos trechos das narrativas dos alunos/participantes para observar o movimento de formação e construção do conhecimento matemático que se vincula na escrita dos discentes em uma perspectiva de tomada de consciência, por parte dos alunos/participantes em relação ao seu processo de ensino/aprendizagem.

Nos trechos das narrativas, pudemos encontrar, em sua maioria, os benefícios e as facilidades que os usos da plataforma do Khan Academy lhes proporcionaram, além de como auxiliaram para a aprendizagem matemática. Assim, qualificamos esse recurso como possibilitador de criação de uma "sala de aula ampliada" (AZEVEDO; PEICO, 2016), na qual o discente pode realizar as atividades e sanar suas dúvidas em suas casas de um modo dinâmico.

Nos fragmentos das narrativas dos alunos/participantes, pudemos observar que o uso da plataforma Khan Academy estabeleceu uma ajuda mútua ao processo de ensino/aprendizagem dos conteúdos matemáticos ensinados e aprendidos no espaço da sala de aula, obtendo, assim, uma aprendizagem satisfatória. A partir das resoluções das situações-problema propostas e dos exercícios resolvidos, os alunos/participantes obtiveram uma aprendizagem mais contextualizada e interativa e com um nível de compreensão dos conceitos matemáticos mais aprofundados alegando:

\footnotetext{
"Acho muito bom as atividades com tecnologia elas ajudam muito no desenvolvimento na aula de matemática, principalmente na prova na plataforma" (aluna do $6^{\circ}$ ano A).

"[...] eu acho que foi legal porque aprendemos bastante coisa como exemplo a apresentação eu aprendi várias coisas e a plataforma também teve vários desafios foi bem legal esta experiência eu gostei bastante eu nunca fiz nada igual adorei nunca fiz nada igual adorei" (aluna do $6^{\circ}$ ano A).

"Acho muito legal trabalhar com tecnologia, principalmente as provas no site Khan Academy" (aluna do $6^{\circ}$ ano A).

"O aplicativo do KHAN ACADEMY é muito boom...Acho bem interessante porque ajuda a gente a aprender mais, exercitar, acho o aplicativo bem melhor do que lição em folha, caderno e tal Assim tem gente que acha difícil o aplicativo, mais eu gosto, é muito interessante gosto demais.... " (aluna do $6^{\circ}$ ano A).
} 
“[...] na plataforma e também, eu consegui aprender várias coisas sobre polígonos regulares e também equação do $1^{\circ}$ grau, bom é isso até agora eu gostei muito dos trabalhos que o professor passou até agora e não tenho nenhuma reclamação" (aluno do $8^{\circ}$ ano B).

"Eu gostei muito, porque o uso da tecnologia melhorou o meu desempenho e provavelmente o desempenho de outros alunos, e também me ajudou muito em provas porque o professor de vez em quando passa a prova na plataforma etc. Enfim, gostei bastante das aulas do professor com o uso de tecnologias" (aluno do $8^{\circ}$ ano D).

“[...] eu achei que as aulas de matemáticas foram muito bem explicadas a plataforma me ajudou muito, acho que as aulas de matemática foram as mais que eu prestei atenção aprendi muito com professor" (aluno do $8^{\circ}$ ano D).

"Minha opinião é que as aulas de matemática estão ótimas com o uso da tecnologia, pois nós podemos aprender mais porque com o uso da plataforma, tendo vídeo lições etc., acho que é mais fácil de estudar" (aluno do $8^{\circ}$ ano D).

A plataforma Khan Academy assemelha-se a um videogame, pois, quanto mais os alunos/participantes realizavam a resolução dos exercícios, mais evoluíam em seus níveis de habilidades e competências e, a partir dessa evolução, seus avatares também evoluíam, o que caracteriza uma aprendizagem lúdica de matemática. Um dos alunos afirma que "foi muito legal, bem que podia voltar a usar a plataforma porque eu gostava de resolver aqueles problemas e evoluir o bichinho e os jogos eram divertidos e educativos" (aluno do $6^{\circ}$ ano B).

Também é possível visualizar algumas críticas na escrita das narrativas dos alunos/participantes devido à falta de acesso na plataforma do Khan Academy, pois ela somente está disponível para uso em computadores e em celulares com sistema iOS, não sendo ofertado seu acesso para celulares com Android. Assim, o acesso foi prejudicado, pois os alunos/participantes em sua maioria não possuíam aparelhos da marca Apple, e sim smartphones com outros sistemas operacionais. Segundo eles: 
"E o site do Khan Academy é o que ajuda mais a gente a se aprofundar, as provas que a gente faz pelo Khan Academy ajuda na nota bastante, porque cada ponto vale 2 , são 5 perguntas e ainda tem dica que vale 1,5, adoraria se tivesse pelo celular no android, só que tem para iphone, gosto muito espero que nos próximos anos tenha mais disso! " (aluna do $6^{\circ}$ ano A).

"De outro lado tem um site super legal chamado Khan Academy que o professor desenvolve atividades (Frações, porcentagem, etc). Bom minha opinião é que os alunos envolvidos com tecnologia têm mais chances de aprender matemática mais rápido, pois hoje em dia os brasileiros são viciados em tecnologia, e estimula os alunos a gostarem mais de matemática, e o melhor do site khan Academy é que podemos fazer provas. A único coisa ruim é que só tem aplicativo para (IOS) e não tem para android" (aluna do $6^{\circ}$ ano A).

"E a plataforma não dava para entra no celular aí complica" (aluno do $8^{\circ}$ ano C).

"[...] achei legal, pois, aprendemos de uma nova forma, ao invés de copiar lousa. As aulas com tecnologia se tornaram mais práticas e eficientes. $\mathrm{O}$ único ponto negativo é que no celular a plataforma não abre" (aluna do $8^{\circ}$ ano $\left.\mathrm{C}\right)$.

Outro ponto relatado por um aluno/participante do $8^{\circ}$ ano é que eles utilizaram somente o celular para acessar a internet, não tendo mais acesso ao computador físico. Ele também mencionou que a plataforma Khan Academy tem carência de explicações mais detalhadas de como realizar a resolução das situações-problema e dos exercícios, fato que podemos concluir que é devido a não compreensão e aprendizagem dos conteúdos matemáticos. Ele pensa que

"Bom as plataformas são muito boas e nos ajuda muito, dando dicas e vídeo para aprender mais e o professor nos ajuda com as dúvidas. Eu acho que deveria ter mais avatares, o site deveria comunicar as escolas para trabalharem mais esta plataforma, e também ter mais exercícios e vídeos mais explicativos" (aluno do $8^{\circ}$ ano B).

Menegais; Fagundes e Sauer (2015, p. 04) mencionam que atividades desenvolvidas a partir da utilização da plataforma Khan Academy estabelecem uma integração das tecnologias 
digitais de informação e comunicação aos currículos escolares de Matemática, podendo transformar o espaço da sala de aula em um lugar "inovador e investigativo, propício à busca da construção de novos conhecimentos, despertando a motivação e proporcionando o desenvolvimento de habilidades cognitivas, tanto do professor, quanto do estudante". Bem como explica Bona (2012, p. 63), o emprego dessa plataforma contribui para o professor com a construção de "conhecimento sobre o ensinar, na reflexão crítica sobre sua prática docente, na dimensão coletiva”.

Por fim, consideramos que o uso da ferramenta da plataforma Khan Academy como um instrumento e recurso tecnológico de auxílio do processo de ensino/aprendizagem da Matemática pode ser uma ocorrência motivacional para os alunos/participantes, expressando, assim, maior proveito e emancipação na construção do conhecimento matemático escolar.

\section{Considerações finais}

Os recursos das plataformas educacionais disponíveis na internet, em particular o Khan Academy, surgem como oportunidade de embasamento ao ensino escolar por possibilitarem abundantes ferramentas para a aprendizagem dos discentes. Soares e Machado (2013, p. 3914) descrevem que, a partir da utilização da plataforma do Khan Academy, o docente também pode aproveitar em sua prática de sala de aula os "conteúdos multimídia, hipertextuais de interação síncrona e assíncrona entre professor/alunos e alunos/ alunos". A plataforma do Khan Academy permitiu que os alunos/ participantes tivessem compromisso e fossem desafiados em sua aprendizagem da Matemática conduzindo uma participação ativa na construção de seu conhecimento matemático, tanto no contexto da sala de aula como fora dela. 


\section{Referências}

AZEVEDO, A. B.; PERICO, L. A. S. Sala de Aula ampliada: além dos limites espaçotemporais escolares. In: AZEVEDO, A. B.; PASSEGI, M. da C. (Org.) Narrativas das experiências docentes com o uso de tecnologia na educação. São Bernardo do Campo: Universidade Metodista de São Paulo, 2016. p. 155-165.

BONA, A. S. Espaço de Aprendizagem Digital da Matemática: o aprender a aprender por cooperação. 2012. 248 f. Tese (Doutorado em Informática na Educação) - Centro de Estudos Interdisciplinares em Novas Tecnologias na Educação da Universidade Federal do Rio Grande do Sul, Porto Alegre, 2012.

FREIRE, P. Pedagogia da Autonomia: Saberes Necessários à Prática Educativa. São Paulo: Paz e Terra, 2011.

HORN, M. B.; STAKER, H. Blended: usando a inovação disruptiva para aprimorar a educação./ Michael B. Horn; Heather Staker; tradução Maria Cristina Gularte Monteiro; revisão técnica Adolfo Tanzi Neto, Lilian Bacich. Porto Alegre: Penso, 2015. 292 p.

JOSSO, M. Da formação do sujeito... Ao sujeito da formação. In: NÓVOA, A.; FINGER, M. (Orgs.) O método (auto)biográfico e a formação. Natal: EDUFRN; São Paulo: Paulus, p. 62-81, 2010. [Pesquisa (auto)biográfica Educação. Clássicos das histórias de vida].

KHAN, S. Um mundo, uma escola: a educação reinventada. Tradução: George Schlesinger. Rio de Janeiro: Intrínseca, 2013. 255p.

MENEGAIS, D. A. F. N.; FAGUNDES, L. C.; SAUER, L. Z. A análise do impacto da integração na plataforma Khan Academy na prática docente de professores de matemática. Revista Novas Tecnologias na Educação (CINTED-UFRGS). Porto Alegre, v. 13, n. 1, p. 01-11, jul. 2015.

PASSEGGI, M. da C.; SOUZA, E. C. de. O método (auto)biográfico: pesquisa e formação. In: NÓVOA, A.; FINGER, M. (Org.) O método (auto)biográfico e a formação. Natal: EDUFRN; São Paulo: Paulus, p. 13-16, 2010. [Pesquisa (auto) biográfica - Educação. Clássicos das histórias de vida]

SOARES, L. S.; MACHADO, M. F. R. C. A utilização do Facebook como suporte ao aprendizado presencial: a visão dos alunos. In: CONGRESSO NACIONAL DE EDUCAÇÃO (EDUCERE), 11., set. 2013, Curitiba. Anais... Curitiba: PUCPR, 2013, p. 3898-3916. Disponível em: <http://educere.bruc.com.br/arquivo/ pdf2013/10092_5100.pdf>. Acesso em: 03 abr. 2017. 
SOUZA, E. C. O conhecimento de si: narrativas do itinerário escolar e formação de professores / por Elizeu C. de Souza. - 2004. 344f. Tese (doutorado) - Universidade Federal da Bahia, Faculdade de Educação, 2004. Disponível em: $<$ https://repositorio.ufba.br/ri/bitstream/ri/10267/1/Tese_Elizeu\%20Souza. pdf>. Acesso em: 05 ago. 2017. 